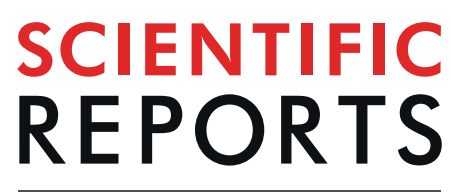

natureresearch

\title{
Green Reduction of Graphene Oxide using Kaffir Lime Peel Extract (Citrus hystrix) and Its Application as Adsorbent for Methylene Blue
}

\begin{abstract}
Ronald Wijaya $\mathbb{D}^{1}$, Gracia Andersan ${ }^{1}$, Shella Permatasari Santoso ${ }^{1,2}$ \& Wenny Irawaty ${ }^{1 *}$
Green reduction of graphene oxide (GO) by phytochemicals was explored using the aqueous extract of kaffir lime peels. The research methods included preparation of extracts, preparation of $\mathrm{GO}$, preparation and characterization of reduced-GO (RGO) using Fourier Transform Infrared (FTIR), X-ray diffraction (XRD), and UV-Vis spectroscopy, as well as methylene blue (MB) adsorption test using RGO. The $\mathrm{RGO}$ characterization showed that $\mathrm{GO}$ was successfully reduced by a $\mathrm{C}=\mathrm{C}$ group restoration. The $\mathrm{MB}$ adsorption kinetics profile in RGO is more suitable for the pseudo-second-order model, whereas for the adsorption isotherm it is more suitable for the Langmuir model with a maximum adsorption capacity $\left(q_{\text {max }}\right)$ of $276.06 \mathrm{mg} / \mathrm{g}$ at room temperature. The best ratio of GO: kaffir lime peel extract used to prepare RGO was at a ratio of $1: 2$. Based on the $\Delta G, \Delta H$, and $\Delta S$ values, the adsorption of RGO-MB was defined as spontaneous and endothermic process. The results promise the potential application of RGO derived via green route to remove cationic dye in wastewater.
\end{abstract}

Methylene Blue (MB) is a cationic dye that has a dark green color ${ }^{1}$. MB is very soluble in water and alcohol and often used as the coloring agent for textiles ${ }^{2}$. Methylene blue can have a negative impact on human body ${ }^{3}$. If inhaled, it can cause respiratory disease, when $\mathrm{MB}$ is accidentally swallowed, it will produce a burning sensation and can cause nausea, vomiting, diarrhea, gastritis, abdominal and chest pain, severe headaches, lots of sweating, mental confusion and methemoglobinemia ${ }^{4}$. Therefore, the presence of $\mathrm{MB}$ in the water needs to be well addressed.

There are several methods used to treat waste from textile water pollution, by ultrafiltration method ${ }^{5}$, ozonization $^{6}$, ion exchange ${ }^{7}$, photocatalysis ${ }^{8}$, and adsorption ${ }^{9}$. Of the many methods, adsorption the most promising method for dealing with textile wastewater; using commercial adsorbents such as activated carbon ${ }^{10}$, zeolites ${ }^{11}$ and nanomagnetic materials ${ }^{11-13}$. In this study, the concentration of $\mathrm{MB}$ in simulated textile wastewater was reduced by the adsorption onto the surface of graphene oxide-based material.

Graphene Oxide $(\mathrm{GO})$ is a carbon nanomaterial that can make strong interaction with organic molecules through hydrogen bonds and $\pi-\pi$ interaction ${ }^{14}$. GO has a stable 2-dimensional structure as electrical and thermal conductors $^{15}$. GO is widely used in many applications such as sensor ${ }^{16}$, catalyst ${ }^{17}$, electronics ${ }^{18}$, water splitting ${ }^{19}$, $\mathrm{CO}_{2}$ reduction ${ }^{20}$, and water treatment ${ }^{17,21}$. The ability of $\mathrm{GO}$ to adsorb $\mathrm{MB}$ is tremendous, with removal efficiency up to $98.8 \%^{14}$. Some modifications can be applied to enhance the ability of GO in MB adsorption, such as composite photocatalyst $\mathrm{t}^{17,22,23}$. A further modification to improve the performance of GO-based materials is essential. GO is heavily decorated by the oxygen functional group $(\mathrm{C}-\mathrm{O})$, and therefore if the oxygen groups can be reduced, the surface area may be expanded. In this state, GO is turned into Reduced Graphene Oxide (RGO).

The conventional method to reduce GO is performed using chemicals such as hydrazine ${ }^{24}$, sodium borohydride $^{25}$, hydroxylamine ${ }^{26}$, etc. The chemical synthesis route offers an efficient method, but the chemicals used are not environmentally friendly. The decrease of RGO performance due to the employment of strong reducing agent during the process has been reported ${ }^{27}$. Thermal treatment is another method to reduce $\mathrm{GO}^{28,29}$. The heat treatment can efficiently remove the oxygen-containing functional groups and thus, open the possibility to fabricate RGO. However, the system requires a high amount of energy as well as complicated experimental set-up.

${ }^{1}$ Department of Chemical Engineering, Widya Mandala Surabaya Catholic University, Kalijudan 37, Surabaya, 60114, Indonesia. ${ }^{2}$ Department of Chemical Engineering, National Taiwan University of Science and Technology, No. 43, Sec.4, Keelung Rd, Da'an District, Taipei City, Taiwan. *email: wenny_i_s@ukwms.ac.id 
Electrochemical reduction offers faster and safer route compared to the previous methods, but its reduction efficiency is reported less than the hydrazine reduction ${ }^{30}$.

Among those methods, the reduction using chemical agents is still the most effective technique for producing RGO. However, the use of hazardous chemicals during RGO can be a problem for the environment ${ }^{27}$. Some natural compounds have been introduced to replace the use of the hazardous reducing agent, i.e. extract of eucalyptus leaves ${ }^{31}$, ascorbic acid $^{32}$, green tea ${ }^{33}$, lemon ${ }^{34}$, etc. However, most bioreducing agents used in RGO preparation are food sources; this raises the possibility of food competition. Therefore, there is still a need to explore non-food sources as reducing agents; agricultural by-products such as peels, seeds, etc, can be a potential source. Herein, we present the RGO preparation using a reducing agent prepared from kaffir lime peel. The reduction of GO using kaffir lime peel extract has not been reported in any literature. Our approach offers several advantages such as eco-friendly reducing agent, simple extract preparation, and non-toxic wastes generated at the end of reduction process.

\section{Materials and Methods}

Materials. Natural graphite powder was supplied by PT. Brataco (Surabaya, Indonesia). Hydrochloric acid (SAP, 37\%), sulfuric acid $\left(\mathrm{H}_{2} \mathrm{SO}_{4}\right.$, CAS 7664-93-9, 99.999\%), hydrogen peroxide $\left(\mathrm{H}_{2} \mathrm{O}_{2}, \mathrm{SAP}, 30 \%\right)$, potassium permanganate $\left(\mathrm{KMnO}_{4}, \mathrm{SAP}, \geq 99.0 \%\right)$, and methylene blue $\left(\mathrm{C}_{16} \mathrm{H}_{18} \mathrm{ClN}_{3} \mathrm{~S}\right.$, CAS 122965-43-9) were used as received. Kaffir lime fruits were obtained from local kaffir lime plantation in Lumajang (East Java, Indonesia).

Preparation of graphene oxide (GO). GO was prepared by using the modified Hummer's method ${ }^{18}$. The

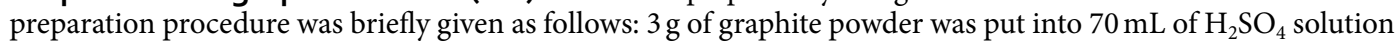
under ice bath conditions with the temperature was set below $20^{\circ} \mathrm{C}$, then $9 \mathrm{~g}$ of $\mathrm{KMnO} 4$ was added to the mixture. Subsequently, the mixture was transferred to an oil bath (Memmert), and the temperature was maintained at $40^{\circ} \mathrm{C}$. During the reaction process, the mixture was continuously stirred at $600 \mathrm{rpm}$ for $30 \mathrm{~min}$. When the reaction was completed, $150 \mathrm{ml}$ of $\mathrm{RO}$ water was added, and the mixture constantly stirred at $600 \mathrm{rpm}$ for $15 \mathrm{~min}$ within $95^{\circ} \mathrm{C}$. Then, $500 \mathrm{~mL}$ of water was added, followed by slow addition of $15 \mathrm{~mL}$ of $\mathrm{H}_{2} \mathrm{O}_{2}(30 \%)$ to remove the residue. A change of solution color was observed from brown to yellowish. The suspension is then filtered and washed with $250 \mathrm{~mL}$ of dilute $\mathrm{HCl}$ solution (1:10). The resulting solid was dried naturally, followed by adding $600 \mathrm{~mL}$ of water. The GO solution was then repeatedly washed with water to remove all residual salts and acids. The neutralized GO solution was stirred overnight, followed by the sonication process to exfoliate the graphite oxide into graphene oxide. The GO dispersion was then stored for the reduction process.

Preparation of kaffir lime peel extract (Citrus hystrix). Twenty-five grams of kaffir lime peels were extracted with $1000 \mathrm{~mL}$ ethanol (41\%) at room temperature for $8 \mathrm{~h}$. The extract was then filtered to separate the solid part and kept in closed container to be further used for GO reduction. Total Phenolic Content (TPC) test was carried out to determine the amount of phenolics in the extract of kaffir lime peels.

Reduction of GO by kaffir lime peel extract (Cytrus hystrix). GO and kaffir lime peel extract was mixed with the GO/extract ratio (v/v) 1:1, 1:2, and 1:4 under vigorous stirring (600 rpm) for $8 \mathrm{~h}$. Subsequently, the mixtures were washed and sonicated for $30 \mathrm{~min}$. This treatment was repeated several times until a clear solution was obtained. Then, the materials were dried in a vacuum oven (Vacucell, 55).

Characterization. Ultraviolet-visible (UV-vis) spectroscopy of GO and RGO was recorded on a Shimadzu UVMINI-1240 spectrophotometer. Crystalline properties of graphite, GO, and RGO were analyzed using X-Ray

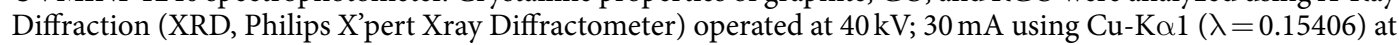
$0.02^{\circ}$ step size and $10.16 \mathrm{~s}$ step time from $5^{\circ}$ to $60^{\circ}$. The surface functional group analysis of the graphite, GO, and RGO was analyzed using Fourier Transform Infrared (FTIR, Shimadzu 8400 S) using KBr powder method. The FTIR spectra were obtained at wavenumber from 1000 to $4000 \mathrm{~cm}^{-1}$.

Preparation of methylene blue (MB) solutions. A stock solution of $1000 \mathrm{mg} / \mathrm{L} \mathrm{MB}$ was made from MB powder, which was dissolved in water. The solution used in the experiment was prepared by diluting the stock solution from $\mathrm{MB}$ to $50 \mathrm{mg} / \mathrm{L}$. The $\mathrm{pH}$ of the solution measured using $\mathrm{pH}$ meter (Metler Toledo).

The experiment of MB adsorption. The contact time effect on MB adsorption was carried out by adding $5 \mathrm{mg}$ RGO into $20 \mathrm{~mL}$ of MB solution with a concentration of $50 \mathrm{mg} / \mathrm{L}$ in a $100 \mathrm{~mL}$ erlenmeyer flask. The flasks were placed in a water bath shaker at $30^{\circ} \mathrm{C}$ (Memmert SV-1422) and shaken until the equilibrium time was reached. At the specified time, the RGO and MB were separated by centrifugation at $4500 \mathrm{rpm}$ for $10 \mathrm{~min}$.

The adsorption isotherm experiment was conducted at room temperature using three variations of RGO (1:1, $1: 2$, and 1:4). The experiment was carried by different addition mass of adsorbent ( $2-12 \mathrm{mg}$, step size: $2 \mathrm{mg}$ ) into a series of erlenmeyer flasks, where each flask contains $20 \mathrm{~mL}$ of MB solution with a concentration of $50 \mathrm{mg} / \mathrm{L}$. These flasks were shaken at $90 \mathrm{rpm}$ until the equilibrium state was achieved. The RGO and MB were separated by centrifugation at $4500 \mathrm{rpm}$ for $10 \mathrm{~min}$. The final concentration of MB was analyzed by UV-Vis spectrophotometer at $665 \mathrm{~nm}$.

The adsorption capacity of RGO was calculated by:

$$
\mathrm{q}_{\mathrm{t}}=\left(\frac{\mathrm{C}_{0}-\mathrm{C}_{\mathrm{t}}}{\mathrm{m}}\right) \times V
$$




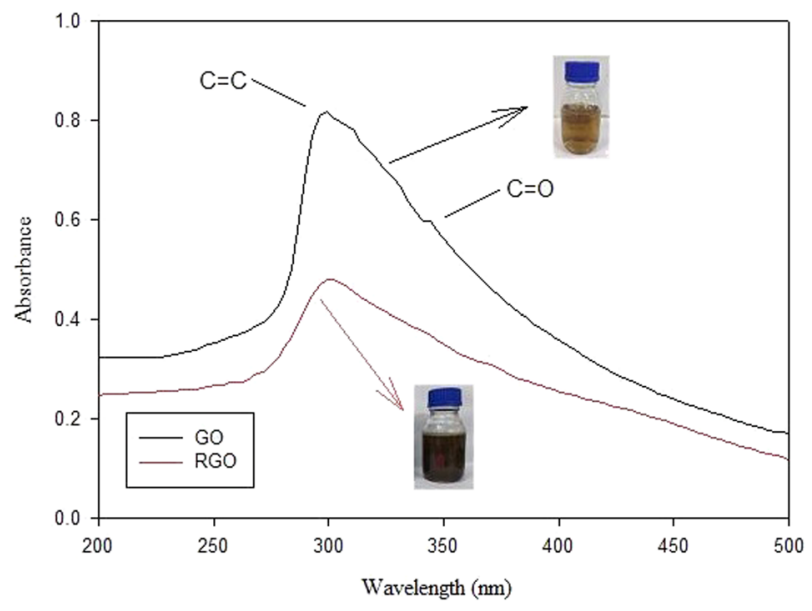

Figure 1. UV-Vis Spectrum of GO and RGO.

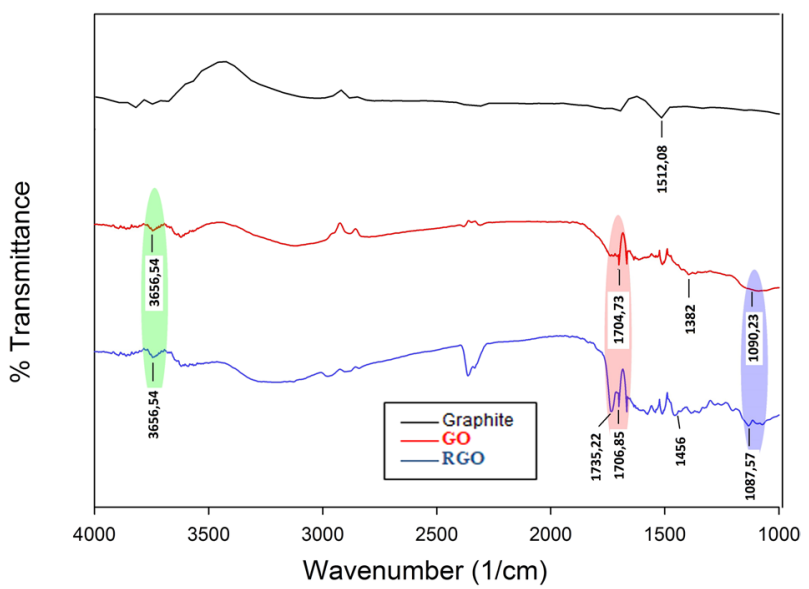

Figure 2. FT-IR spectra of graphite, GO, and RGO.

where $C_{o}(\mathrm{mg} / \mathrm{L})$ is an initial concentration of $\mathrm{MB}, C_{t}(\mathrm{mg} / \mathrm{L})$ is the concentration of $\mathrm{MB}$ at time $t, m(\mathrm{~g})$ adsorbent quantity, and $V(\mathrm{~L})$ is the volume of MB solution. At a constant value of $C_{t}$, the parameter of $C_{t}$ and $q_{t}$ becomes $C_{e}$ and $q_{e}$, where $C_{e}(\mathrm{mg} / \mathrm{L})$ is the equilibrium concentration of $\mathrm{MB}$.

\section{Results and Discussion}

Characterization of graphene materials. UV-Vis spectroscopic analysis was carried out to monitor changes in functional groups from GO to RGO. It can be seen from Fig. 1 that the peak transition $\pi \rightarrow \pi^{*}$ for graphitic groups on GO was detected at a wavelength of $\sim 300 \mathrm{~nm}$. The shoulder peak at $\sim 343 \mathrm{~nm}$ representing $\mathrm{n} \rightarrow \pi^{*}$ for the $\mathrm{C}=\mathrm{O}$ group, indicates the presence of a $\mathrm{C}-\mathrm{O}$ functional group in $\mathrm{GO}^{32}$. The $\mathrm{GO}$ transformation into RGO was confirmed by loss of the shoulder peak, where the C-O group in RGO has been reduced. The transformation of GO to RGO was also supported by the change of GO solution color, which was initially brown to blackish after being reduced by kaffir lime peels extract.

The surface functional groups of graphite, GO, and RGO were obtained by Fourier Transform Infrared (FTIR) analysis. Fig. 2 shows the presence of several functional groups in the three samples tested. The results of FTIR analysis summarized in Table 1 showed the presence of $\mathrm{C}=\mathrm{C}$ groups in graphite at the peak of $1512.08 \mathrm{~cm}^{-1}$. The formation of $\mathrm{GO}$ was indicated by the presence of a hydroxyl group at $3656.54 \mathrm{~cm}^{-1}$, a carbonyl group $(\mathrm{C}=\mathrm{O})$ at $1704.73 \mathrm{~cm}^{-1}$, an alkene group $(=\mathrm{CH})$ at $1090.23 \mathrm{~cm}^{-1}$, and ester group $(\mathrm{C}-\mathrm{O})$ at $1382 \mathrm{~cm}^{-1}$. The GO reduction process into RGO caused the aromatic group $(\mathrm{C}=\mathrm{C})$ restored by the emergence of $1456 \mathrm{~cm}^{-1}$ and $1735.22 \mathrm{~cm}^{-1}$ peaks in RGO. The change of the peak indicates that the GO was successfully reduced to RGO ${ }^{35}$. FTIR analysis shows that there are still $\mathrm{C}=\mathrm{O}$ groups remained on the reduced $\mathrm{GO}$; this signifies that the GO reduction partially occurred. However, it is still unclear as to whether $\mathrm{C}=\mathrm{O}$ persists even after suffering a reduction. A similar phenomenon was experienced by Aliyev et al., where the $\mathrm{RGO}$ produced still has $\mathrm{C}=\mathrm{O}$ groups remaining even after reduction using hydrazine monohydrate ${ }^{36}$. Dreyer and group suggest that in the process of GO reduction, the reducing agent can breakdown the epoxy groups of GO and produce carbonyl groups ${ }^{37}$.

The X-Ray Diffraction (XRD) analysis was conducted to determine the crystallinity of graphite, GO, and RGO. The peak point of the GO is determined based on the degree of oxidation and the exfoliation process. It can be 


\begin{tabular}{|l|l|l|l|}
\hline \multirow{2}{*}{ Functional Group } & \multicolumn{3}{|l|}{ Wavenumber $(\mathbf{1} / \mathrm{cm})$} \\
\cline { 2 - 4 } & Graphite & GO & RGO \\
\hline Alkane C-C & 1502.73 & - & - \\
\hline Hydroxyl $(\mathrm{O}-\mathrm{H})$ & - & 3656.54 & 3656.54 \\
\hline Carbonyl $(\mathrm{C}=\mathrm{O})$ & - & 1704.73 & 1706.85 \\
\hline Alkene $(=\mathrm{C}-\mathrm{H})$ & - & 1090.23 & 1087.57 \\
\hline Ester $(\mathrm{C}-\mathrm{O})$ & - & 1382 & - \\
\hline Aromatic $(\mathrm{C}=\mathrm{C})$ & - & - & 1456 \\
\hline Aromatic $(\mathrm{C}=\mathrm{C})$ & - & - & 1735.22 \\
\hline
\end{tabular}

Table 1. The surface functional groups of Graphite, GO and RGO.

\begin{tabular}{|c|c|c|}
\hline Sample & $2 \theta$ (degree) & Spacing-d (Á) \\
\hline Graphite & 26.45 & 3.37 \\
\hline $\mathrm{GO}$ & 10.11 & 8.75 \\
\hline \multirow[t]{2}{*}{ RGO } & \begin{tabular}{|l|}
8.75 \\
\end{tabular} & 10.10 \\
\hline & 26.34 & 3.38 \\
\hline
\end{tabular}

Table 2. Peak result of XRD pattern for Graphite, GO, and RGO.
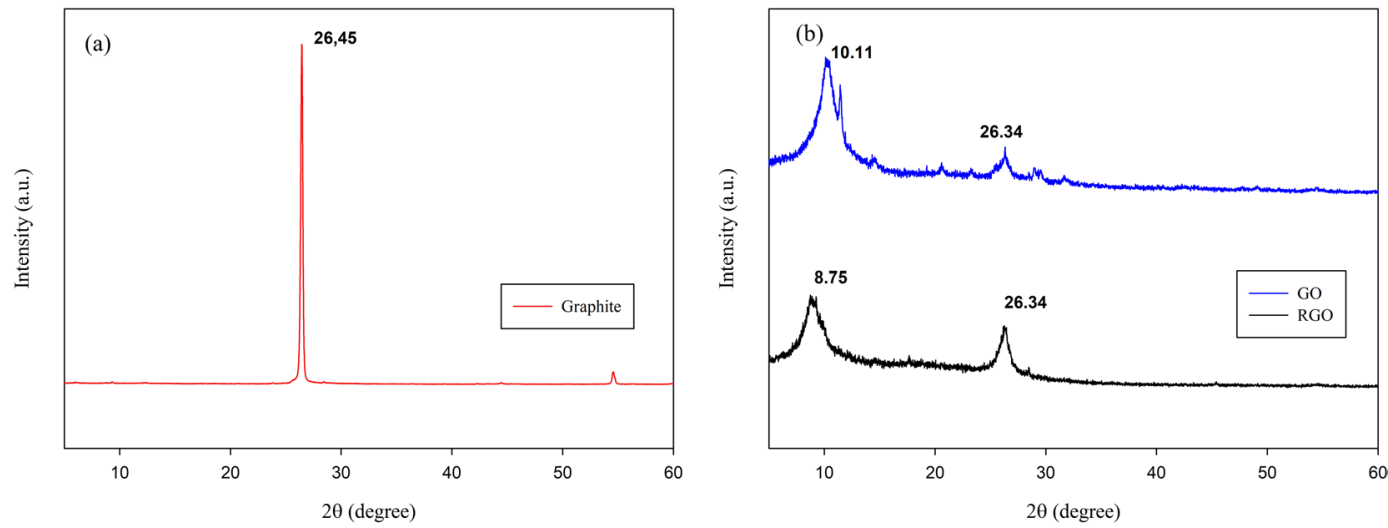

Figure 3. XRD patterns of (a) graphite (b) GO and RGO.

seen from Fig. 3 and Table 2 that graphite, which initially had a sharp graphitic peak at $26.45^{\circ}$ and spacing of 3.35 Á. After being synthesized became GO, the graphitic peak in $26.45^{\circ}$ was found disappear, and new peak appeared at $10.11^{\circ}$ with lots of diffraction. This indicates that synthesized graphite into GO undergoes peak shifting due to the oxidation and intercalation process of epoxy, hydroxyl, etc. ${ }^{32}$. The spacing or distance between layers that

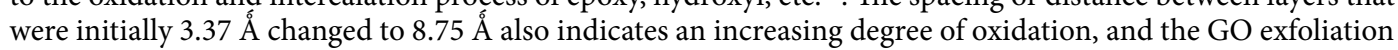
process is getting stronger ${ }^{38}$. After being reduced being RGO it was found that the peak point in the area of $10.11^{\circ}$ has broadened, and the graphitic peak intensity at $26.34^{\circ}$ is increasing. Thus it can be indicated that the reduction process, there is a degradation in $\mathrm{C}-\mathrm{O}$ groups and the restoration of the $\mathrm{C}=\mathrm{C}$ bond structure.

Adsorption kinetic study. The adsorption kinetic curve of MB over RGO are shown in Fig. 4. It can be seen that the adsorption equilibrium time was reached after $420 \mathrm{~min}$. The adsorption kinetics parameter was determined using the pseudo-first and the pseudo-second-order models. These models are calculated using the following equations:

$$
\begin{gathered}
\text { pseudo-first } \log (q e-q t)=\log q e-\frac{k_{1}}{2.303} t \\
\text { pseudo-second } \frac{t}{q t}=\frac{1}{k_{2} q e^{2}}+\frac{t}{q e}
\end{gathered}
$$

The parameters of the adsorption kinetics of MB over RGO are summarized in Table 3. Based on the sum square error (SSE), physisorption is the dominant process controlled the adsorption of MB on RGO. In reverse, if the model obtained refers to pseudo-second-order, then RGO-MB will tend to the mechanism of chemisorption $^{39}$. The equilibrium state of MB adsorption on RGO obtained in kinetic experiment is used as reference time in adsorption isotherm process. 


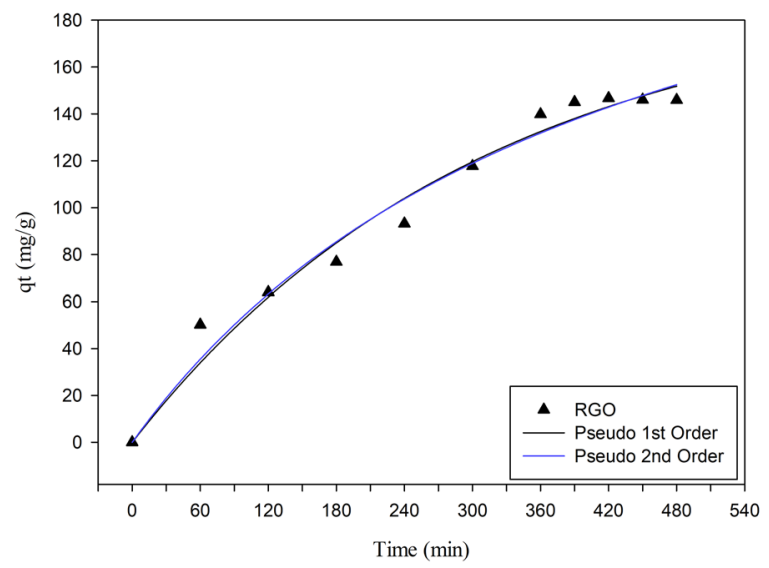

Figure 4. Adsorption kinetics of MB adsorption onto RGO.

\begin{tabular}{|l|l|c|}
\hline Kinetic Model & Parameters & Value \\
\hline \multirow{4}{*}{ Pseudo-first-order } & $q e(\mathrm{mg} / \mathrm{g})$ & 192.79 \\
\cline { 2 - 3 } & $k_{1}(1 / \mathrm{min})$ & 0.0032 \\
\cline { 2 - 3 } & SSE & 606.53 \\
\hline \multirow{3}{*}{ Pseudo-second-order } & $q e(\mathrm{mg} / \mathrm{g})$ & 288.11 \\
\cline { 2 - 3 } & $k_{2}(\mathrm{~g} / \mathrm{mg} \mathrm{min}) \times 10^{-6}$ & 8.12 \\
\cline { 2 - 3 } & SSE & 582.92 \\
\hline
\end{tabular}

Table 3. Parameters of the pseudo-first-order and pseudo-second-order kinetic model for MB adsorption.

From the pseudo-first-order model, the $q e$ value is $192.79 \mathrm{mg} / \mathrm{g}$, and the $k_{1}$ value is $0.0032 \mathrm{~min}^{-1}$ with SSE of 606.53. Meanwhile, the pseudo-second-order equation obtained qe of $288.11 \mathrm{mg} / \mathrm{g}$ and $k_{2}$ value of $8.12((\mathrm{~g} / \mathrm{mg}$ $\mathrm{min}) \times 10^{-6}$ ) with SSE of 582.92. From the comparison of SSE values in the kinetic model used, the RGO adsorption kinetics is more in line with the pseudo-second-order, which means that the adsorption process of RGO-MB was more controlled by chemisorption.

Isotherm adsorption study. The adsorption isotherm of RGO was carried out to study the interaction between adsorbate and adsorbent. Adsorption isotherm was carried out with a span of $420 \mathrm{~min}$, where this time is equilibrium time as obtained from the adsorption kinetics data. The adsorption isotherm was modeled using the Langmuir and Freundlich models. The Freundlich and Langmuir model can be represented mathematically as follows:

$$
\begin{gathered}
\text { Freundlich } q_{e}=K_{f} C_{e}^{1 / n} \\
\text { Langmuir } q_{e}=q_{\max } \frac{\left(K_{L} C e\right)}{1+K_{L} C e}
\end{gathered}
$$

In the Freundlich model, $K_{f}$ represents the adsorption capacity of the adsorbent, and $n$ showed the heterogeneity and adsorption intensity of RGO. In the Langmuir model, $q_{\max }$ represents the maximum adsorption capacity, $K_{L}$ states the Langmuir constant. The result of isotherm adsorption of RGO-MB is presented in Fig. 5a and Fig. 5c, and the calculated parameters are summarized in Table 4.

Based on the SSE obtained, it can be seen the SSE of the Langmuir model is smaller than the SSE of the Freundlich model. Also, a small $n$ value indicates that the adsorbent heterogeneity is minimal and tends to be homogeneous. This shows the uniformity of the adsorption surface that supports conformity with the Langmuir model. The affinity of the adsorption between $\mathrm{RGO}-\mathrm{MB}$ is determined by the $\mathrm{K}_{\mathrm{L}}$ parameter where the value is very small; which supports the results of data $n$ from the Freundlich model, where small $n$ is indicating that the adsorbent more less intensity to adsorb the adsorbate. It can be concluded that the Langmuir isotherm model is the most suitable model for the $\mathrm{MB}$ adsorption process using RGO. The process of adsorption of MB by RGO studied tends to be slow.

Table 4 shows the relationship of the variation in concentration to the adsorption capacity. At a ratio of 1:1, the adsorption capacity $\left(\mathrm{q}_{\max }\right)$ was found $228.07 \mathrm{mg} / \mathrm{g}$, at a concentration of $1: 2 \mathrm{q}_{\max }$, the higher adsorption capacity was obtained $(276.06 \mathrm{mg} / \mathrm{g})$ and decreased at a ratio of $1: 4$. This can be possible that the CO group present in the GO has not been completely reduced in the concentration of 1:1, whereas at the ratio of 1:4 the reduced GO is at 

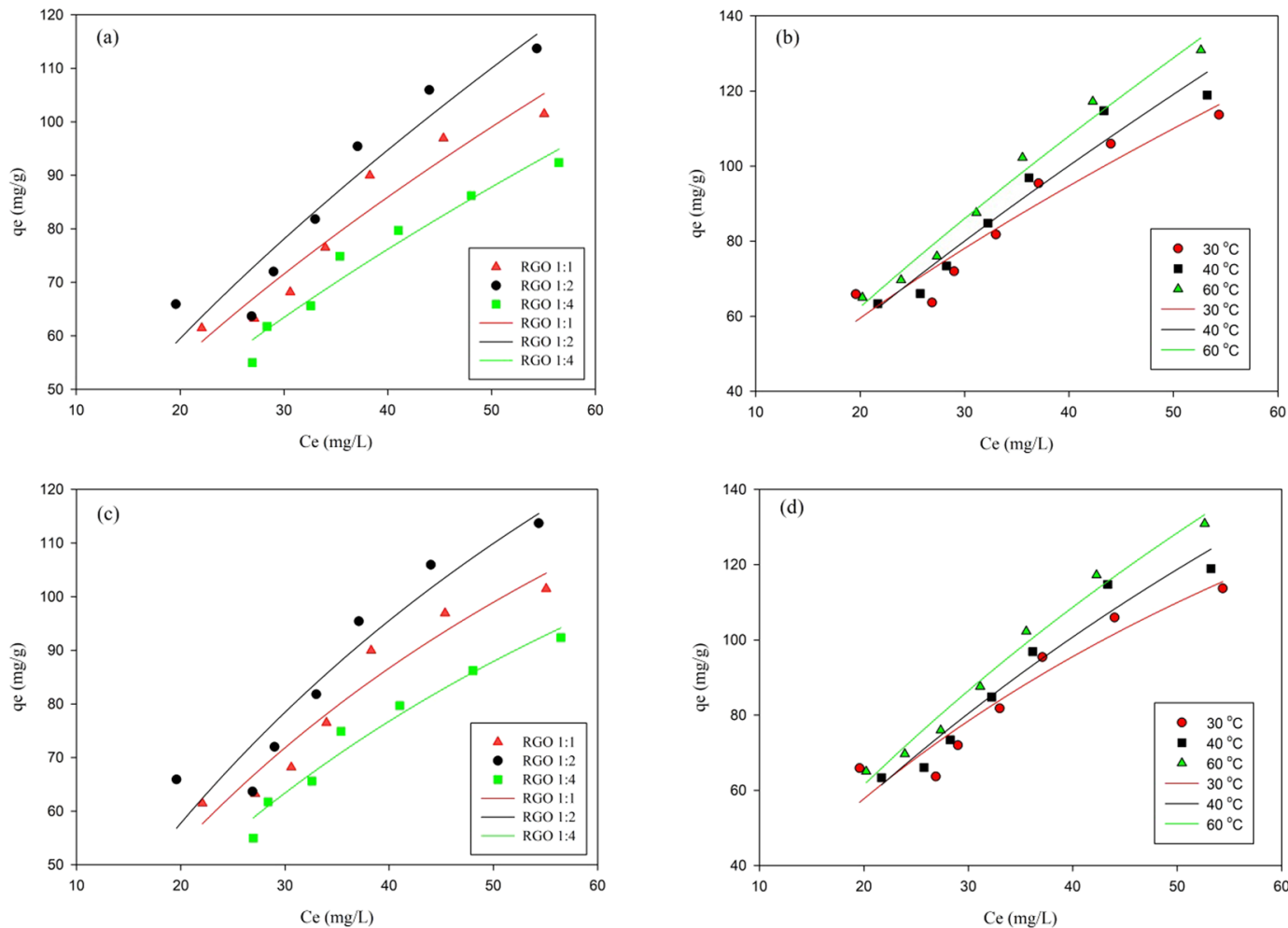

Figure 5. Adsorption isotherm of $\mathrm{MB}$ adsorption onto RGO. (a) Freundlich model at different ratio of GO/ extract (b) Freundlich model at different temperatures (c) Langmuir model at different ratio of GO/extract (d) Langmuir model at different temperatures.

\begin{tabular}{|l|l|l|l|l|l|l|}
\hline \multirow{2}{*}{ Adsorbent } & \multicolumn{4}{|l|}{ Freundlich } & \multicolumn{2}{l|}{ Langmuir } \\
\cline { 2 - 7 } & $\mathbf{n}$ & $\mathbf{K}_{\mathbf{F}}(\mathbf{L} / \mathbf{g})$ & SSE & $\mathbf{q}_{\max }(\mathbf{m g} / \mathbf{g})$ & $\mathbf{K}_{\mathbf{L}}(\mathbf{L} / \mathbf{g})$ & SSE \\
\hline RGO 1:1 & 1.57 & 8.23 & 111.73 & 228.07 & 0.015 & 104.41 \\
\hline RGO 1:2 & 1.49 & 7.98 & 227.54 & 276.06 & 0.013 & 213.06 \\
\hline RGO 1:4 & 1.57 & 7.29 & 51.44 & 209.34 & 0.014 & 39.00 \\
\hline
\end{tabular}

Table 4. Parameters of Freundlich and Langmuir isotherm adsorption model for MB adsorption.

the saturated condition. The adsorption capacity of MB using various RGO suggests that RGO 1:2 has the best performance to remove $\mathrm{MB}$.

The ability of RGO to adsorb MB was compared to other studied adsorbents, as shown in Table 5. RGO produced in this study exhibited relative higher of adsorption capacity compared to other adsorbents. For the same target adsorbate (MB), up to $276 \mathrm{mg}$ of $\mathrm{MB}$ can be adsorbed on the surface of RGO; which is much higher than the adsorption capacity of nanocomposite of $\beta$-cyclodextrin/magnetic graphene oxide, that is only $94 \mathrm{mg} / \mathrm{g}$. The photocatalyst $\mathrm{Fe}_{3} \mathrm{O}_{4}-\mathrm{RGO}-\mathrm{TiO}_{2}$, only able to adsorp $1.67 \mathrm{mg} \mathrm{MB}$ per gram of particle. However, the use of activated seagrass Posidonia oceanica waste can achieve almost ten times higher than our adsorbent ${ }^{40}$. The high adsorption capacity of RGO (this study) can be explained by its high specific surface area, i.e. $3127 \mathrm{~m}^{2} / \mathrm{g}$ as measured by the Brunauer-Emmett-Teller method. The significantly increased of the specific surface area from GO $\left(832 \mathrm{~m}^{2} / \mathrm{g}\right)$ to RGO has facilitated the MB adsorption. This result suggests that kaffir lime peel extract is potent to be used as the bioreducing agent to modify GO for MB adsorption. Further study to elucidate the mechanism of reduction activity performed by phytochemicals of kaffir lime peels is required.

Adsorption thermodynamics. Adsorption thermodynamics proceeds to evaluate the effect of temperature due to adsorption process of RGO-MB. The thermodynamics parameter is calculated using following equations:

$$
\begin{gathered}
\Delta \mathrm{G}=-\mathrm{RT} \ln K_{L} \\
\Delta \mathrm{G}=\Delta \mathrm{H}=\Delta \mathrm{S} . \mathrm{T} \\
\ln \left(K_{L}\right)=\ln \left(\frac{Q e}{C e}\right)=\frac{\Delta \mathrm{S}}{R}-\frac{\Delta \mathrm{H}}{R T}
\end{gathered}
$$




\begin{tabular}{|c|c|c|}
\hline Adsorbents & $\begin{array}{l}\text { Adsorption } \\
\text { capacity }(\mathrm{mg} / \mathrm{g})\end{array}$ & References \\
\hline Graphene $/ \mathrm{SrAl}_{2} \mathrm{O}_{3}: \mathrm{Bi}^{3+}$ & 42.92 & 17 \\
\hline$\beta$-cyclodextrin/MGO & 93.97 & 43 \\
\hline $\mathrm{g}-\mathrm{C}_{3} \mathrm{~N}_{4}($ Melamine $)$ & 1.64 & 44 \\
\hline g- $\mathrm{C}_{3} \mathrm{~N}_{4}$ (Thiourea) & 1.87 & 44 \\
\hline $\mathrm{g}-\mathrm{C}_{3} \mathrm{~N}_{4}($ Urea $)$ & 2.51 & 44 \\
\hline $\mathrm{TiO}_{2} / \mathrm{Na}-\mathrm{g}-\mathrm{C}_{3} \mathrm{~N}_{4}$ & 1.8 & 45 \\
\hline $\begin{array}{l}\text { Magnetic carboxyl functional } \\
\text { nanoporous polymer }\end{array}$ & 57.74 & 46 \\
\hline Activated Posidonia oceanica waste & $2,681.90$ & 40 \\
\hline $\mathrm{CeO}_{2}$ & 4.37 & 47 \\
\hline $\mathrm{Fe}_{3} \mathrm{O}_{4}-\mathrm{RGO}-\mathrm{TiO}_{2}$ & 1.67 & 48 \\
\hline $\mathrm{Ag}-\mathrm{Fe}_{3} \mathrm{O}_{4}$-polydopamine & 45 & 23 \\
\hline RGO $1: 2$ & 276.06 & Present work \\
\hline
\end{tabular}

Table 5. Adsorption capacity of several adsorbents to adsorp methylene blue.

\begin{tabular}{|c|c|c|c|}
\hline $\mathbf{T}(\mathbf{K})$ & $\Delta \mathrm{G}\left(\mathrm{kJ} \mathrm{\textrm {mol } ^ { - 1 } )}\right.$ & $\Delta \mathrm{H}\left(\mathrm{kJ} \mathrm{mol}^{-1}\right)$ & $\Delta S\left(\mathrm{~J} \mathrm{~mol}^{-1} \mathrm{~K}^{-1}\right)$ \\
\hline 303 & -5.98 & 19.15 & 82.93 \\
\hline 313 & -6.81 & & \\
\hline 333 & -8.47 & & \\
\hline
\end{tabular}

Table 6. Thermodynamics parameters for MB adsorption onto RGO.

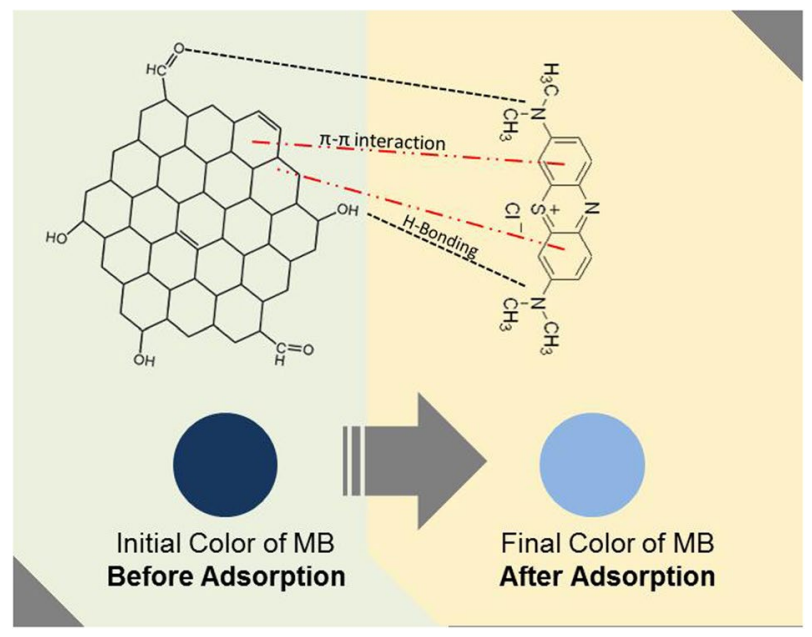

Figure 6. $\mathrm{MB}$ adsorption mechanism using RGO.

where $\mathrm{R}$ is the universal gas constant $\left(8.314 \mathrm{~J} \mathrm{~mol}^{-1} \mathrm{~K}^{-1}\right)$ and $T$ is absolute temperature $(\mathrm{K}) . \Delta \mathrm{H}\left(\mathrm{kJ} \mathrm{mol}{ }^{-1}\right)$, $\Delta \mathrm{S}\left(\mathrm{J} \mathrm{mol}^{-1} \mathrm{~K}^{-1}\right)$, and $\Delta \mathrm{G}\left(\mathrm{kJ} \mathrm{mol}^{-1}\right)$ are enthalpy, entropy, and Gibbs free energy, respectively. $\Delta \mathrm{H}$ and $\Delta \mathrm{S}$ were calculated from the slope and intercept of $\ln \left(K_{L}\right)$ versus $1 / T$ which was represented in Fig. 5b, and Fig. $5 \mathrm{~d}$. As seen in Table 6 , the $\Delta \mathrm{G}$ value was found to be $-5.98 \mathrm{~kJ} \mathrm{~mol}^{-1}$ at $303 \mathrm{~K}$ and decrease to $-8.47 \mathrm{~kJ} \mathrm{~mol}^{-1}$ at $333 \mathrm{~K}$. The negative values of $\Delta \mathrm{G}$ indicates the $\mathrm{MB}$ adsorption onto RGO is spontaneous. The value of $\Delta \mathrm{H}$ and $\Delta \mathrm{S}$ was found to be $19.15 \mathrm{~kJ} \mathrm{~mol}^{-1}$ and $82.93 \mathrm{~J} \mathrm{~mol}^{-1} \mathrm{~K}^{-1}$, respectively. The positive value of $\Delta \mathrm{H}$ and $\Delta \mathrm{S}$ can be related to the adsorption mechanism of RGO-MB ${ }^{41}$ as seen in Fig. 6, where the positive value of $\Delta \mathrm{H}$ also represents that RGO-MB adsorption process was endothermic.

The high adsorption capacity of RGO is attributed to $\pi-\pi$ interaction between MB molecule and the surface of $\mathrm{RGO}^{14}$. The high area exhibited by RGO favors the $\pi-\pi$ electron donor interaction between the molecule of MB and RGO. Accordingly, the adsorption of MB on the surface of RGO could go up to $276 \mathrm{mg} / \mathrm{g}$. In addition, electrostatic forces caused by difference in surface charge between MB and RGO also support the adsorption process. In aqueous solution, $\mathrm{MB}$ will exist as positively charged ions, while RGO tends to be negatively charged in water and thus, this has facilitated the electrostatic force between the two ${ }^{42}$. 


\section{Conclusions}

The reduction: of GO to RGO by using kaffir lime peel extract as a bioreductor was successfully carried out. The ratio of bioreductor and reduction time has been observed to influence the characteristics of RGO, and the optimal conditions were found to be $1: 2$ and $8 \mathrm{~h}$, respectively. Analyses of UV-Vis Spectroscopy, FTIR, and XRD indicated the reduction of $\mathrm{GO}$ to $\mathrm{RGO}$ by the $\mathrm{C}=\mathrm{C}$ group restoration. The adsorption study performed on $\mathrm{MB}$ showed that the maximum adsorption capacity $\left(\mathrm{q}_{\max }\right)$ of RGO was found $276.06 \mathrm{mg} / \mathrm{g}$. MB adsorption by RGO followed pseudo-second-order model; whereas, for the isotherm, the system prefers in line with the Langmuir model. The RGO-MB adsorption interaction is more dominantly controlled by chemisorption. The adsorption of RGO-MB was a spontaneous and endothermic process. The present study indicates RGO prepared by bioreduction of RG using kaffir lime peels extract a potential adsorbent to remove MB and therefore, it can be further developed for industrial applications.

Received: 3 October 2019; Accepted: 31 December 2019;

Published online: 20 January 2020

\section{References}

1. Shahwan, T. et al. Green synthesis of iron nanoparticles and their application as a Fenton-like catalyst for the degradation of aqueous cationic and anionic dyes. Chem. Eng. J. 172, 258-266, https://doi.org/10.1016/j.cej.2011.05.103 (2011).

2. Tiwari, J. N. et al. Reduced graphene oxide-based hydrogels for the efficient capture of dye pollutants from aqueous solutions. Carbon 56, 173-182, https://doi.org/10.1016/j.carbon.2013.01.001 (2013).

3. El Qada, E. N., Allen, S. J. \& Walker, G. M. Adsorption of methylene blue onto activated carbon produced from steam activated bituminous coal: A study of equilibrium adsorption isotherm. Chem. Eng. J. 124, 103-110, https://doi.org/10.1016/j.cej.2006.08.015 (2006).

4. Ghosh, D. \& Bhattacharyya, K. G. Adsorption of methylene blue on kaolinite. Appl. Clay Sci. 20, 295-300, https://doi.org/10.1016/ S0169-1317(01)00081-3(2002).

5. Vinodhini, P. A. \& Sudha, P. N. Removal of heavy metal chromium from tannery effluent using ultrafiltration membrane. Textiles and Clothing Sustainability 2, 5, https://doi.org/10.1186/s40689-016-0016-3 (2016).

6. Yurteri, C. \& Gurol, M. D. Removal of dissolved organic contaminants by ozonation. Environ. Prog. 6, 240-245, https://doi. org/10.1002/ep.670060411 (1987).

7. Padmavathi, R., Minnoli, M. \& Sangeetha, D. Removal of heavy metal ions from waste water using anion exchange polymer membranes. Int. J. Plast. Technol. 18, 88-99, https://doi.org/10.1007/s12588-014-9067-y (2014).

8. Wang, C.-C., Li, J.-R., Lv, X.-L., Zhang, Y.-Q. \& Guo, G. Photocatalytic organic pollutants degradation in metal-organic frameworks. Energ. Environ. Sci. 7, 2831-2867, https://doi.org/10.1039/C4EE01299B (2014).

9. Lee, J.-Y., Chen, C.-H., Cheng, S. \& Li, H.-Y. Adsorption of $\mathrm{Pb}(\mathrm{II})$ and $\mathrm{Cu}(\mathrm{II})$ metal ions on functionalized large-pore mesoporous silica. Int. J. Environ. Sci. Technol. 13, 65-76, https://doi.org/10.1007/s13762-015-0841-y (2016).

10. Singh, K. P., Mohan, D., Sinha, S., Tondon, G. S. \& Gosh, D. Color removal from wastewater using low-cost activated carbon derived from agricultural waste material. Ind. Eng. Chem. Res. 42, 1965-1976, https://doi.org/10.1021/ie020800d (2003).

11. Meshko, V., Markovska, L., Mincheva, M. \& Rodrigues, A. E. Adsorption of basic dyes on granular acivated carbon and natural zeolite. Water Res. 35, 3357-3366, https://doi.org/10.1016/S0043-1354(01)00056-2 (2001).

12. Afkhami, A., Saber-Tehrani, M. \& Bagheri, H. Modified maghemite nanoparticles as an efficient adsorbent for removing some cationic dyes from aqueous solution. Desalin. 263, 240-248, https://doi.org/10.1016/j.desal.2010.06.065 (2010).

13. Qadri, S., Ganoe, A. \& Haik, Y. Removal and recovery of acridine orange from solutions by use of magnetic nanoparticles. J. Hazard. Mater. 169, 318-323, https://doi.org/10.1016/j.jhazmat.2009.03.103 (2009).

14. Li, Y. et al. Comparative study of methylene blue dye adsorption onto activated carbon, graphene oxide, and carbon nanotubes. Chem, Eng. Res. Des. 91, 361-368, https://doi.org/10.1016/j.cherd.2012.07.007 (2013).

15. Pei, S. \& Cheng, H.-M. The reduction of graphene oxide. Carbon 50, 3210-3228, https://doi.org/10.1016/j.carbon.2011.11.010 (2012).

16. Cai, L. et al. Synthesis of Fe3O4/graphene oxide/pristine graphene ternary composite and fabrication electrochemical sensor to detect dopamine and hydrogen peroxide. Chem. Phys. Lett. 736, 136797, https://doi.org/10.1016/j.cplett.2019.136797 (2019).

17. Oliva, J. et al. Flexible graphene composites for removal of methylene blue dye-contaminant from water. Appl. Surf. Sci. 436, 739-746, https://doi.org/10.1016/j.apsusc.2017.12.084 (2018).

18. Chen, J., Yao, B., Li, C. \& Shi, G. An improved Hummers method for eco-friendly synthesis of graphene oxide. Carbon 64, 225-229, https://doi.org/10.1016/j.carbon.2013.07.055 (2013).

19. Kuang, P., He, M., Zou, H., Yu, J. \& Fan, K. OD/3D MoS 2 -NiS $/ 2$-doped graphene foam composite for efficient overall water splitting. Appl. Catal. B. 254, 15-25, https://doi.org/10.1016/j.apcatb.2019.04.072 (2019).

20. Bie, C., Zhu, B., Xu, F., Zhang, L. \& Yu, J. In situ grown monolayer N-doped graphene on CdS hollow spheres with seamless contact for photocatalytic $\mathrm{CO}_{2}$ reduction. Adv. Mater. 31, 1902868, https://doi.org/10.1002/adma.201902868 (2019).

21. Zheng, Y., Cheng, B., You, W., Yu, J. \& Ho, W. 3D hierarchical graphene oxide-NiFe LDH composite with enhanced adsorption affinity to Congo red, methyl orange and Cr(VI) ions. J. Hazard. Mater. 369, 214-225, https://doi.org/10.1016/j.jhazmat.2019.02.013 (2019).

22. Yang, X. et al. Rapid degradation of methylene blue in a novel heterogeneous $\mathrm{Fe}_{3} \mathrm{O}_{4} @ \mathrm{rGO} @ \mathrm{TiO}_{2}$-catalyzed photo-Fenton system. Sci. Rep. 5, 10632, https://doi.org/10.1038/srep10632 (2015).

23. Wu, M., Li, Y., Yue, R., Zhang, X. \& Huang, Y. Removal of silver nanoparticles by mussel-inspired Fe $\mathrm{O}_{4} @$ polydopamine core-shell microspheres and its use as efficient catalyst for methylene blue reduction. Sci. Rep. 7, 42773, https://doi.org/10.1038/srep42773 (2017).

24. Park, S. et al. Hydrazine-reduction of graphite- and graphene oxide. Carbon 49, 3019-3023, https://doi.org/10.1016/j. carbon.2011.02.071 (2011).

25. Shin, H.-J. et al. Efficient reduction of graphite oxide by sodium borohydride and its effect on electrical conductance. Adv. Funct. Mater. 19, 1987-1992, https://doi.org/10.1002/adfm.200900167 (2009).

26. Zhou, X. et al. Reducing graphene oxide via hydroxylamine: A simple and efficient route to graphene. J. Phys. Chem. C 115, 11957-11961, https://doi.org/10.1021/jp202575j (2011).

27. Kuila, T. et al. Chemical functionalization of graphene and its applications. Prog. Mater. Sci. 57, 1061-1105, https://doi.org/10.1016/j. pmatsci.2012.03.002 (2012).

28. Zhu, Y. et al. Exfoliation of graphite oxide in propylene carbonate and thermal reduction of the resulting graphene oxide platelets. ACS Nano 4, 1227-1233, https://doi.org/10.1021/nn901689k (2010).

29. McAllister, M. J. et al. Single sheet functionalized graphene by oxidation and thermal expansion of graphite. Chem. Mater. 19, 4396-4404, https://doi.org/10.1021/cm0630800 (2007). 
30. An, S. J. et al. Thin film fabrication and simultaneous anodic reduction of deposited graphene oxide platelets by electrophoretic deposition. J. Phys. Chem. Lett. 1, 1259-1263, https://doi.org/10.1021/jz100080c (2010).

31. Jin, X., Li, N., Weng, X., Li, C. \& Chen, Z. Green reduction of graphene oxide using eucalyptus leaf extract and its application to remove dye. Chemosphere 208, 417-424, https://doi.org/10.1016/j.chemosphere.2018.05.199 (2018).

32. De Silva, K. K. H., Huang, H.-H. \& Yoshimura, M. Progress of reduction of graphene oxide by ascorbic acid. Appl. Surf. Sci. 447, 338-346, https://doi.org/10.1016/j.apsusc.2018.03.243 (2018).

33. Tai, M. J.-Y. et al. Green synthesis of reduced graphene oxide using green tea extract. AIP Conference Proceedings 2045, 020032, https://doi.org/10.1063/1.5080845 (2018).

34. Hou, D., Liu, Q., Cheng, H. \& Li, K. Graphene synthesis via chemical reduction of graphene oxide using lemon extract. J. Nanosci. Nanotechnol. 17, 6518-6523, https://doi.org/10.1166/jnn.2017.14426 (2017).

35. Jana, M. et al. Bio-reduction of graphene oxide using drained water from soaked mung beans (Phaseolus aureus L.) and its application as energy storage electrode material. Mater. Sci. Eng. B. 186, 33-40, https://doi.org/10.1016/j.mseb.2014.03.004 (2014).

36. Aliyev, E. et al. Structural characterization of graphene oxide: Surface functional groups and fractionated oxidative debris. Nanomaterials 9, 1180, https://doi.org/10.3390/nano9081180 (2019).

37. Dreyer, D. R., Park, S., Bielawski, C. W. \& Ruoff, R. S. The chemistry of graphene oxide. Chem. Soc. Rev. 39, 228-240, https://doi. org/10.1039/b917103g (2010)

38. Abdolhosseinzadeh, S., Asgharzadeh, H. \& Seop Kim, H. Fast and fully-scalable synthesis of reduced graphene oxide. Sci. Rep. 5, 10160, https://doi.org/10.1038/srep10160 (2015).

39. Ho, Y. S. \& McKay, G. Pseudo-second order model for sorption processes. Process Biochem. 34, 451-465, https://doi.org/10.1016/ S0032-9592(98)00112-5 (1999).

40. Elmorsi, R. R. et al. Adsorption of methylene blue and $\mathrm{Pb}^{2+}$ by using acid-activated Posidonia oceanica waste. Sci. Rep. 9, 3356, https://doi.org/10.1038/s41598-019-39945-1 (2019).

41. Ma, T., Chang, P. R., Zheng, P., Zhao, F. \& Ma, X. Fabrication of ultra-light graphene-based gels and their adsorption of methylene blue. Chem. Eng. J. 240, 595-600, https://doi.org/10.1016/j.cej.2013.10.077 (2014).

42. McCoy, T. M. et al. Bulk properties of aqueous graphene oxide and reduced graphene oxide with surfactants and polymers: adsorption and stability. Phys. Chem. Chem. Phys. 20, 16801-16816, https://doi.org/10.1039/C8CP02738B (2018).

43. Ma, Y.-X. et al. One-step fabrication of $\beta$-cyclodextrin modified magnetic graphene oxide nanohybrids for adsorption of $\mathrm{Pb}(\mathrm{II})$, $\mathrm{Cu}(\mathrm{II})$ and methylene blue in aqueous solutions. Appl. Surf. Sci. 459, 544-553, https://doi.org/10.1016/j.apsusc.2018.08.025 (2018).

44. Zhu, B., Xia, P., Ho, W. \& Yu, J. Isoelectric point and adsorption activity of porous g- $\mathrm{C}_{3} \mathrm{~N}_{4}$. Appl. Surf. Sci. 344, 188-195, https://doi. org/10.1016/j.apsusc.2015.03.086 (2015).

45. Liu, H. et al. Fabrication of surface alkalinized $\mathrm{g}-\mathrm{C}_{3} \mathrm{~N}_{4}$ and $\mathrm{TiO}_{2}$ composite for the synergistic adsorption-photocatalytic degradation of methylene blue. Appl. Surf. Sci. 473, 855-863, https://doi.org/10.1016/j.apsusc.2018.12.162 (2019).

46. Su, H., Li, W., Han, Y. \& Liu, N. Magnetic carboxyl functional nanoporous polymer: synthesis, characterization and its application for methylene blue adsorption. Sci. Rep. 8, 6506, https://doi.org/10.1038/s41598-018-24873-3 (2018),

47. Wei, X. et al. Different adsorption-degradation behavior of methylene blue and Congo red in nanoceria/ $\mathrm{H}_{2} \mathrm{O}_{2}$ system under alkaline conditions. Sci. Rep. 9, 4964, https://doi.org/10.1038/s41598-018-36794-2 (2019).

48. Yang, X. et al. Rapid degradation of methylene blue in a novel heterogeneous $\mathrm{Fe}_{3} \mathrm{O}_{4} @ \mathrm{rGO} @ \mathrm{TiO}_{2}$-catalyzed photo-Fenton system. Sci. Rep. 5, 10632, https://doi.org/10.1038/srep10632 (2015).

\section{Acknowledgements}

This work was supported by the Ministry of Research, Technology, and Higher Education (RISTEKDIKTI) Indonesia through Student Creativity Program 2019 (RR, GA) and Research Grant No. 200B/WM01.5/N/2019 (WI).

\section{Author contributions}

R.W. and G.A. carried out the experiments and wrote the main manuscript. W.I. and S.P.S. finalized and revised the manuscript. All authors have reviewed and approved the manuscript.

\section{Competing interests}

The authors declare no competing interests.

\section{Additional information}

Correspondence and requests for materials should be addressed to W.I.

Reprints and permissions information is available at www.nature.com/reprints.

Publisher's note Springer Nature remains neutral with regard to jurisdictional claims in published maps and institutional affiliations.

(c) (i) Open Access This article is licensed under a Creative Commons Attribution 4.0 International (c) License, which permits use, sharing, adaptation, distribution and reproduction in any medium or format, as long as you give appropriate credit to the original author(s) and the source, provide a link to the Creative Commons license, and indicate if changes were made. The images or other third party material in this article are included in the article's Creative Commons license, unless indicated otherwise in a credit line to the material. If material is not included in the article's Creative Commons license and your intended use is not permitted by statutory regulation or exceeds the permitted use, you will need to obtain permission directly from the copyright holder. To view a copy of this license, visit http://creativecommons.org/licenses/by/4.0/.

(C) The Author(s) 2020 